Jeje TO, et al.

\title{
Article
}

\section{Aqueous extract of Phyllanthus niruri protects against severe malaria by blocking erythrocyte invasion and modulating the host immune response}

Keywords: apoptosis, IFN- $\gamma$, invasion, Phyllanthus niruri, Plasmodium, NF-кB,

Jeje Temitope Olawale ${ }^{1,2,3, \dagger}$, Hironori Bando $^{1, \dagger}$, Yasuhiro Fukuda ${ }^{1}$, Ibukun Emmanuel Oluwafemi $^{3}$, Kentaro Kato ${ }^{1, *}$

${ }^{1}$ Laboratory of Sustainable Animal Environment, Graduate School of Agricultural Science, Tohoku University, 232-3 Yomogida, Naruko-onsen, Osaki, Miyagi 989-6711, Japan.

${ }^{2}$ Department of Biochemistry, Faculty of Science, Federal University Oye-Ekiti, Nigeria.

${ }^{3}$ Department of Biochemistry, School of Science, Federal University of Technology, Akure, Nigeria.

${ }^{\dagger}$ Contributed equally.

\section{Running title: anti-Plasmodium effects of $\boldsymbol{P}$. niruri extract}

Keywords: apoptosis, IFN- $\gamma$, invasion, Phyllanthus niruri, Plasmodium, NF-кB,

\section{Correspondence should be addressed to:}

Kentaro Kato, D.V.M., Ph.D.

Laboratory of Sustainable Animal Environment, Graduate School of Agricultural Science, Tohoku University, 232-3 Yomogida, Naruko-onsen, Osaki, Miyagi 989-6711, Japan.

Phone: +81-229-84-7391, Fax: +81-229-84-7391,

E-mail: kentaro.kato.c7@tohoku.ac.jp 


$$
\text { Jeje TO, et al. }
$$

\section{ABSTRACT}

Plasmodium falciparum parasites are the major cause of malaria across Africa. Due to the appearance of multi-drug resistant parasites, new antimalarial drugs are needed. The medicinal plant Phyllanthus niruri is being used to treat fever and other symptoms of malaria in Nigeria; however, little is known about its antimalarial mechanisms. Here, we show that aqueous extract of $P$. niruri (PE) has multiple antimalarial effects, including anti-parasitic and host immunomodulatory activity. We found that co-culture of $P$. falciparum with PE drastically reduced parasite number, but PE did not inhibit parasite development or rupture; rather, it blocked erythrocytes invasion. In addition, we identified Astragalin as one of the antimalarial compounds which are contained in PE. Moreover, we found that PE suppresses the inflammatory activity and apoptosis of immune cells (T cells) and astrocytes and neurons in the central nervous system (CNS). Furthermore, we confirmed that oral administration of PE to mice suppressed parasite growth, excessive inflammation, CNS dysfunction, and the development of experimental cerebral malaria in an in vivo murine malaria model. Our findings demonstrate that PE has multiple effects on malaria progression, targeting both parasite and host cells. 
Jeje TO, et al.

\section{INTRODUCTION}

Malaria is one of the most prevalent vector-borne infectious diseases; it is caused by the obligatory protozoan malaria parasite Plasmodium. The 2018 World Health Organization (WHO) report estimated that there were 405,000 deaths and 213 million cases of malaria around the world, and $90 \%$ of all malaria cases have occurred in sub-Saharan Africa ${ }^{1}$. Although human malaria is usually caused by four species of Plasmodium parasite-P. falciparum, $P$. vivax, $P$. malariae, and $P$. ovale - the majority of infections are caused by $P$. falciparum ${ }^{2}$. In addition, infection with $P$. falciparum can cause severe anemia, cerebral malaria (CM), and acute respiratory distress syndrome ${ }^{3-5}$. Although there is currently no licensed malaria vaccine, some effective antimalarial drugs have been discovered, including quinine, which was extracted from the Cinchona tree ${ }^{6}$ and artemisinin, which was discovered in the Chinese plant Artemisia annua ${ }^{7}$. Thus, antimalarial drugs from medicinal plants have contributed to malaria control. However, the appearance of drug-resistant parasites has posed serious problems in recent years ${ }^{8}$, prompting the WHO to recommend artemisinin-based combination therapies (ACTs) for the treatment of malaria. Although most antimalarial drugs target the parasite inside the erythrocyte, at least one study suggests that an attractive target for therapeutic development is the step of merozoite erythrocyte invasion ${ }^{9}$, because inhibition of invasion would prolong exposure of the parasites to the immune system and drugs ${ }^{10,11}$. However, few antimalarial drugs target parasite erythrocyte 
Jeje TO, et al.

invasion and new antimalarial therapeutics with targets that differ from those of existing antimalarial drugs are needed.

Historically, anti-pathogenic activity has been found in various medicinal plants ${ }^{11}$. In fact, some medicinal plants have been used for the treatment of malaria in endemic areas even though the science behind their efficacy is unclear ${ }^{12,13}$, suggesting that extracts from medicinal plants might be a promising source of new antimalarial compounds. Phyllanthus niruri L. (Euphorbiaceae) is a prevalent tropical plant ${ }^{14}$ with recognized medicinal properties ${ }^{15}$, being used for malaria treatment in some endemic areas. For example, in Nigeria, an aqueous extract obtained from the whole $P$. niruri plant has been used to prevent severe malaria or reduce malaria symptoms. Although, some previous studies have suggested that treatment with extract of $P$. niruri reduces the number of $P$. falciparum in vitro and murine $P$. berghei malaria in $v^{\text {vivo }}{ }^{15,16}$, the detailed mechanisms by which $P$. niruri inhibits parasite growth or suppresses the development of severe malaria are largely unknown.

P. falciparum infection induces dysfunction of the central nervous system (CNS), by, for example, disrupting the blood-brain-barrier (BBB) and causing neuronal damage in the brain, leading to $\mathrm{CM}^{17}$. P. falciparum-associated pathologies such as $\mathrm{CM}$ are the result of the complicated interaction between the host immune system and the parasite growth. Previous studies have shown that the development of CM is related to dysregulation of the immune system in a murine malaria model of experimental cerebral malaria $(\mathrm{ECM})^{18,19}$. Mechanistic 
studies of ECM progression have reported that the expression of the inflammatory cytokine interferon- $\gamma(\mathrm{IFN}-\gamma)$ is critical for the development of ECM, because IFN- $\gamma$ receptor-deficient mice are completely protected from ECM-dependent death ${ }^{20,21}$. In addition, it has been reported that $\mathrm{T}$ cell activation and production of $\mathrm{IFN}-\gamma$ are important for $\mathrm{BBB}$ disruption ${ }^{22-24}$. Thus, dysregulation of BBB function could cause the flow of cytokines, immune cells, and other toxic materials into the brain parenchyma, inducing CNS inflammation ${ }^{25}$. Therefore, an immunomodulatory approach to the suppression of Plasmodium-induced inflammation might be useful for malaria therapy. Moreover, a recent study suggested that the host cell is an attractive antimalarial drug target that could potentially prevent the acquisition of drug resistance by parasites $^{26}$. Thus, the discovery of new antimalarial drug candidates with not only anti-parasitic activity but also host immunomodulatory activity is highly desirable.

Here, we found that aqueous extract of $P$. niruri (PE) can prevent the development of severe malaria by targeting both parasite and host cells. PE exerts anti-parasitic activity by blocking erythrocyte invasion by merozoites, and it read to inhibit CM progression. Importantly, both of these effects are driven by a different mechanism of action from that of most of the current antimalarial drugs, including artemisinin. Taken together, our data suggest that $P$. niruri might be useful in ACTs for malaria treatment and is a promising source for new antimalarial compounds. 
Jeje TO, et al.

\section{RESULTS}

\section{PE treatment inhibits $P$. falciparum growth in vitro.}

The effect of $P$. niruri on Plasmodium parasite growth is largely unknown. Therefore, to test whether $P$. niruri has an anti-parasitic effect, freeze-dried aqueous $P$. niruri extracts (PE) were prepared (Fig. 1A). Previous reports indicated that PE does not show any toxicity in vitro or in vivo ${ }^{27,28}$. We confirmed that no significant cytotoxicity was observed at a concentration of $200 \mu \mathrm{g} / \mathrm{ml}$ PE against primary human foreskin fibroblasts (HFFs) (Fig. 1B). Next, to test the anti-parasitic activity of PE, P. falciparum were cultured with $200 \mu \mathrm{g} / \mathrm{ml}$ PE for 96 hours and then subjected to a growth inhibition assay (GIA) (Fig. 1C). As previously reported, PE treatment resulted in a significant reduction in the numbers of parasites compared with the nontreated condition (Fig. 1C and Fig. S1A). In addition, we found that the $\mathrm{IC}_{50}$ value of PE for $P$.

falciparum inhibition was $35.11 \mu \mathrm{g} / \mathrm{ml}$ (Fig. 1D). A previous study reported that the extraction of P. niruri showed higher antimalarial activity $\left(\mathrm{EC}_{50}: 2.9-4.1 \mu \mathrm{g} / \mathrm{ml}\right)$ compared to our result $\left(\mathrm{EC}_{50}\right.$ : $35.11 \mu \mathrm{g} / \mathrm{ml})^{16}$. This disparity may be as a result of the difference in the materials and experimental procedure. For example, it is known that the metabolic profiles of $P$. niruri change with its geographical distribution ${ }^{14}$. Thus, we chose to use our materials and experimental procedure because our method and materials are suitable for detecting the effect and function of traditionally used $P$. niruri in Nigeria. 


$$
\text { Jeje TO, et al. }
$$

\section{PE affects erythrocyte invasion by $P$. falciparum.}

GIA is usually used to measure the comprehensive ability of a drug to inhibit parasite invasion, rupture, and/or development ${ }^{29}$. Therefore, to test whether the PE has an effect on parasite development inside the erythrocytes, synchronized ring formed parasites (immature trophozoites) were cultured with PE for 24 hours, and then compared the morphology of the parasites (Fig. 2A). There was no observable effect of the PE on the morphology of the parasites (Fig. 2A) or parasitemia (Fig. S2A), indicating that point of action of the PE is not parasite development into schizonts inside the erythrocytes. Next, we examined whether the PE has an effect on erythrocytes invasion by parasites. Synchronized schizonts were cultured with PE for 24 hours, and then parasitemia was assessed (Fig. 2B). PE treatment strongly reduced the parasite numbers (Fig. 2B). In addition, most of the infected parasites were not at the schizont stage but ring formed (data not shown), indicating that there was no effect of PE on parasite rupture or egress. Because erythrocyte invasion by parasites requires an interaction between host receptors and parasite ligands ${ }^{30}$, we assessed whether PE has an effect on erythrocyte surface receptors. The erythrocytes were treated with PE for 1 hour and then washed and cultured with infected erythrocytes for 24 hours (Fig. 2C). We found that pre-washed erythrocytes lost the ability to inhibit parasite invasion (Fig. 2C), suggesting that PE does not have an effect on erythrocyte surface receptors but on the parasite ligands or the parasite invasion processes. 


$$
\text { Jeje TO, et al. }
$$

\section{Astragalin affects erythrocyte invasion by $P$. falciparum.}

Astragalin, Catechin, Niranthin and Quercetin have been reported to be abundantly identified in our study plant ${ }^{14}$. They are examples of polyphenolic compounds identified to be the constituent of the most active fraction of $P$. niruri $^{31}$. We therefore subjected these compounds to invasion inhibition assay. We found that Astragalin and Quercetin, but not Catechin and Niranthin, had an antimalarial activity (Fig. 2D). Then we examined the antimalarial function of Astragalin and Quercetin. Astragalin showed an invasion inhibition activity with a mechanism similar to that of the aqueous extract of P. niruri (Fig. 2E). On the other hands, Quercetin showed its antiplasmodial effect by direct killing of the schizont, hence there was little or no egress (Fig. 2E). Taken together, we identified that Astragalin has an antimalarial activity in the similar way as PE. In addition, because we also found that $P$. niruri contains a number of antimalarial compounds, we focused on the antimalarial activity and function of whole plant (PE) extract to evaluate the effect and function of traditionally used $P$. niruri in natural.

\section{PE suppresses the activity of NF-kB dependent pro-inflammatory gene expression in $T$ cells.}

We attempted to gain further insight into the mechanism by which PE prevents the development of severe malaria. Excessive gene or protein expression of pro-inflammatory cytokines, such as IFN- $\gamma$, has an important role in the dysregulation of the immune system and BBB destruction during Plasmodium infection ${ }^{17,23}$. Because $\mathrm{T}$ cells are an important source of 
Jeje TO, et al.

IFN- $\gamma$ to disrupt the $\mathrm{BBB}^{32}$, we examined the effect of PE on a human T-lymphoid cell line (MOLT-4). We first confirmed that PE treatment caused no significant cytotoxicity in MOLT-4 cells (Fig. 3A). Then, to assess whether PE treatment has an effect on IFN- $\gamma$ gene expression, we cultured MOLT-4 cells with PMA and ionomycin for 3 hours (Fig. 3B). Although PMA/ionomycin co-stimulation showed marked induction of IFN- $\gamma$ expression in PE non-treated MOLT-4 cells, PE treatment strongly suppressed IFN- $\gamma$ induction (Fig. 3B), suggesting that PE plays an important role in the suppression of $\mathrm{T}$ cell inflammatory responses. NF- $\mathrm{B}$ activation and its translocation from the cytoplasm to the nucleus is involved in IFN- $\gamma$ expression ${ }^{33}$. Therefore, we co-stimulated PE-treated or non-treated MOLT-4 cells with PMA/ionomycin and compared the localization of NF- $\kappa \mathrm{B}$ p65/RelA protein (Fig. 3C). The translocation of NF- $\kappa \mathrm{B}$ p65/RelA protein to the nuclear compartment was observed in PE non-treated MOLT-4 cells that were co-stimulated with PMA/ionomycin. In sharp contrast, nuclear translocation of NF- $\mathrm{BB}$ p65/RelA was not observed in PE-treated MOLT-4 cells (Fig. 3C). To confirm the effect of PE on NF- $\mathrm{KB}$ activation, we generated a luciferase reporter plasmid harboring element dependent on NF- $\kappa \mathrm{B}$ transcription factors. Then, we compared the luciferase activity induced by PMA/ionomycin co-stimulation in reporter plasmid-transfected MOLT-4 cells that were left untreated or were treated with PE (Fig. 3D). Although the luciferase activity in the PE nontreated MOLT-4 cells was increased by PMA/ionomycin stimulation, that in the PE-treated MOLT-4 cells was inhibited (Fig. 3D). In addition, there were no differences in the levels of NF- 
Jeje TO, et al.

$\kappa \mathrm{B}$ mRNA but significant differences in the levels of $\mathrm{I} \kappa \mathrm{B}-\alpha$, which is involved in the inhibition

of NF- $\kappa \mathrm{B}$ nuclear translocation ${ }^{34}$ (Fig. S3A). These results suggest that PE affects not the expression levels of NF- $\kappa \mathrm{B}$ mRNA but the activation and/or nuclear translocation of NF- $\mathrm{B}$.

\section{PE blocks inflammatory activity and apoptosis in the CNS.}

The activation of astrocytes, a type of glial cell in the CNS, plays an important role in the progression of $\mathrm{CM}^{35}$. We confirmed that PE treatment caused no significant cytotoxicity in the human astrocyte cell line U-251 (Fig. 4A). Then, to assess whether PE treatment had an effect on IFN- $\gamma$ gene expression, we cultured U-251 cells with PMA and ionomycin for 3 hours (Fig. 4B). Although co-stimulation with PMA/ionomycin markedly induced IFN- $\gamma$ expression in PE non-treated U-251 cells, PE treatment inhibited IFN- $\gamma$ induction (Fig. 4B), suggesting that PE also suppresses the inflammatory responses of astrocytes. CM progression induces neuronal apoptosis, leading to neuropathology $\mathrm{y}^{35,36}$. We confirmed that PE treatment caused no significant cytotoxicity in the human neuron cell line IMR-32 (Fig. 4C). Then, to test whether PE could prevent neuronal apoptosis, we cultured IMR-32 cells with staurosporine with or without PE. Then, we compared the activity of caspase $3 / 7$, which are proteases that initiate and execute $\operatorname{apoptosis}^{37}$ (Fig. 4D). We found that PE treatment severely reduced staurosporine-induced caspase 3/7 activity, indicating that PE inhibited the activation of the apoptotic pathway in neuron cells. 


\section{Jeje TO, et al.}

\section{PE has in vivo antimalarial effects against murine $P$. berghei malaria.}

Finally, we tested whether PE treatment could control the development of CM in vivo.

At first, we assessed the immunomodulatory activity of PE by mice sepsis model because Sepsis progression has been linked to IFN- $\gamma$ release, which is also responsible for systemic inflammatory syndrome through its ability to enlarge proinflammatory response ${ }^{38}$. We found out that the level of IFN- $\gamma$ in the serum of PE treated group of mice was significantly reduced compared to the non-treated group (Fig. S4A). Then, we assessed the antimalarial activity of PE by experimental cerebral malaria (ECM). The murine malaria parasite $P$. berghei ANKA was used to infect C57BL/6 (B6) mice, which are known to be a good model for $\mathrm{ECM}^{19}$. When Mock- or PE-treated mice were challenged with $P$. berghei-infected erythrocytes, the PE-treated mice exhibited reduced parasitemia (Fig. 5A) and higher survival rates (Fig. 5B). In addition, we found that there was significantly reduced disruption of the BBB in PE-treated mice (Fig. 5C). Furthermore, serum IFN- $\gamma$ levels in $P$. berghei-infected mice were significantly reduced in the presence of PE (Fig. 5D). Taken together, these results indicate that PE induces multiple in vivo effects to prevent $\mathrm{CM}$ progression, including inhibition of parasite growth, suppression of excessive inflammation, and prevention of CNS dysfunction. 
Jeje TO, et al.

\section{DISCUSSION}

The present study showed that an aqueous extract of $P$. niruri (PE) has multiple effects, both direct and indirect, against the disease progression pathway of severe malaria. PE has a direct effect in that it targets the parasite, by inhibiting erythrocyte invasion, and an indirect effect in that it targets the host via its immunomodulatory activity to suppress excessive inflammation and prevent CNS disfunction.

Over the years, antimalarial drugs against the blood stage of $P$. falciparum have been used for the treatment of malaria ${ }^{29,39}$. However, new antimalarial drugs are still required because of the emergence of multi-drug resistant parasites ${ }^{9,40}$. Accordingly, new candidate antimalarial drugs have been sought. Medicinal plants are a recognized repository of drug lead compounds against various diseases including malaria ${ }^{41,42}$. Scientific evaluation of these natural pharmaceuticals can offer an effective and low-cost route to obtain drugs for the treatment of diseases, including malaria ${ }^{12}$. One such medicinal plant, Phyllanthus niruri, is being used for antimalarial therapy in Nigeria. In this study, we confirmed the anti-parasitic activity of PE by using a $P$. falciparum GIA, which suggested that PE might have potential as an antimalarial drug. The life cycle of the Plasmodium parasite in the host is separated into two different stages: the liver-stage and the blood-stage. The blood-stage is also known as the clinical stage ${ }^{43}$, in contrast to the liver stage, which is sometimes termed the silent stage ${ }^{44}$. Plasmodium merozoites repeat the cyclic process of erythrocyte invasion, development, and rupture, leading 
Jeje TO, et al.

to lysis of the erythrocytes and severe anemia. Thus, although each step in the life cycle of the blood-stage parasite is attractive as an anti-parasitic target because it is an essential event for parasite infection, most of the existing antimalarial drugs target parasite development ${ }^{9,45}$. In contrast, little has been reported about compounds that target erythrocyte invasion by parasites.

One report suggested that the chemical compound YA29 can affect erythrocyte invasion by merozoites; ${ }^{46}$ however, another study suggested that YA29 affects the rupture of schizonts ${ }^{47}$, and therefore, the mechanism of action of YA29 remains controversial. In the present study, we found that PE has an effect on erythrocyte invasion by parasites. Importantly, although the Plasmodium GIA is capable of detecting PE efficacy with respect to inhibition of invasion, development, and/or rupture ${ }^{29}$, it clearly showed that PE does not have an effect on the development and rupture of parasites. Furthermore, we found that PE did not have any effect on the erythrocyte cell surface receptors during the invasion process despite both the host receptor and parasite ligand being important for the erythrocyte invasion step ${ }^{30}$. This result is important for ensuring low cytotoxicity because inhibition of the function of erythrocyte cell surface receptors could lead to problems such as inducing hemolysis and prevention of the interaction with $\mathrm{Fc}$ receptors on phagocytic macrophages ${ }^{48}$. In addition, we found that Astragalin and Quercetin, which were found to be abundantly identified in this plant ${ }^{31}$, are active compounds against Plasmodium parasite. Because both compounds have never been reported as antimalarial compound, it is an important finding. Notably, we discovered that Astragalin is a novel active 
Jeje TO, et al.

compound against Plasmodium with parasite invasion inhibition activity. This mechanism of antimalarial activity is quite an important finding because there is no such mechanism of action among the existing anti-malarial drugs and little is known about compounds which has such an activity. Taken together, these result strongly suggest that PE may have potential for use in combination with current antimalarial drugs, particularly ACTs because the antimalarial mechanisms of artemisinin is completely different ${ }^{49}$.

There are two major severe malaria symptoms caused by $P$. falciparum infection: severe malarial anemia and CM. Several malarial anemia involves multiple factors among which is direct disruption of erythrocytes by parasite growth ${ }^{4}$. In contrast, CM is an immune-mediated pathology, which is indirectly caused by the $P$. falciparum infection-dependent immune dysfunction $^{50}$. Our study and some other previous ones have shown that PE directly affects $P$. falciparum growth ${ }^{15,16}$; however, the immunomodulatory role of $\mathrm{PE}$ during Plasmodium infection has been unclear. Some previous studies have reported that $P$. falciparum infection induces excessive secretion of the pro-inflammatory cytokine IFN- $\gamma$ from immune cells or glial cells of the $\mathrm{CNS}^{22,25,51}$, thereby resulting in BBB disruption and CNS dysfunction. Thus, the prevention of severe malaria progression may hinge on how well the excessive inflammatory response is controlled ${ }^{52}$. In fact, immunomodulators that downregulate the hyper-activated immune system caused by parasite infection have had variable success ${ }^{53}$. Interestingly, PE has previously been reported to attenuate pro-inflammatory cytokine release from activated 
Jeje TO, et al.

macrophages ${ }^{54}$, suggesting the possibility that PE might be involved in immune modulation during malaria infection. In the present study, we found that PE suppressed IFN- $\gamma$ expression in both T cells (immune cells) and astrocytes (major glial cells in the CNS) and also in vivo LPSinduced mouse sepsis. Some phytochemicals, such as flavonoid compounds, have been reported as immunomodulators that downregulate pro-inflammatory cytokine expression through inactivation of $\mathrm{NF}-\mathrm{KB}^{55,56}$. Our study showed that PE-dependent inhibition of IFN- $\gamma$ gene expression is also mediated by preventing NF- $\kappa \mathrm{B}$ activation, suggesting the possibility that PE contains flavonoid or flavonoid-like compounds. In addition to excessive inflammatory activity, $\mathrm{CM}$ leads to a severe neuropathology caused by neuronal apoptotic cell death, and, therefore, protection of neurons from apoptosis is also important for preventing severe malaria progression. In the present study, we showed that PE functions to protect neurons from apoptotic signals. Furthermore, we showed that PE has both anti-parasitic effects and immunomodulatory effects in vivo by using a murine malaria model. Notably, our in vivo results were obtained by using a simple method with real-life applicability: aqueous extraction of $P$. niruri and oral administration. P. niruri is widely distributed and easily obtained in endemic areas. Moreover, aqueous extraction of $P$. niruri and its oral administration is simple and low cost; therefore, these processes are feasible and readily applicable to most endemic areas. Thus, our study suggests that aqueous extraction of $P$. niruri would be useful for the integrated management of severe malaria. 
Jeje TO, et al.

In summary, here we demonstrated that PE can provide protection from the development of severe malaria via multiple effects, including inhibition of erythrocyte invasion by parasites and suppression of CNS dysfunction both in vitro and in vivo. PE can not only be readily applied in endemic areas as a medicinal plant against malaria, but it may also contribute to the development of future next-generation antimalarial drugs because it may contain one or more useful antimalarial compounds. 
Jeje TO, et al.

\section{MATERIALS AND METHODS}

\section{Ethics statement}

The animal experiments were approved by the Animal Research Committee of Tohoku University and conducted in accordance with the ARRIVE and specific institutional guidelines.

\section{Mice, cells, and parasites}

Six-week-old female C57BL/6N mice were obtained from Charles River Laboratories Japan. All animal experiments were conducted with the approval of the Animal Research Committee of Tohoku University. MOLT-4 cells were maintained in RPMI (Nacalai Tesque) containing $10 \%$ heat-inactivated FBS, $100 \mathrm{U} / \mathrm{ml}$ penicillin, and $0.1 \mathrm{mg} / \mathrm{ml}$ streptomycin. U-251 cells were maintained in MEM (Invitrogen) containing $10 \%$ heat-inactivated FBS, $100 \mathrm{U} / \mathrm{ml}$ penicillin, and $0.1 \mathrm{mg} / \mathrm{ml}$ streptomycin, as previously described ${ }^{57}$. IMR-32 cells were maintained in MEM (Invitrogen) containing 10\% heat-inactivated FBS, 1\% NEAA (Invitrogen), 100 U/ml penicillin, and $0.1 \mathrm{mg} / \mathrm{ml}$ streptomycin, as previously described ${ }^{57} . P$. berghei ANKA and $P$. falciparum HB3 clone were obtained from the Malaria Research and Reference Reagent Resource Center (MR4; American Type Culture Collection, Manassas, VA). The parasites were cultured in medium containing RPMI 1640, $25 \mathrm{mM}$ HEPES, $100 \mu \mathrm{M}$ hypoxanthine, $12.5 \mu \mathrm{g} / \mathrm{ml}$ gentamicin sulfate supplemented with $5 \%(\mathrm{w} / \mathrm{v})$ Albumax I, and $62.5 \mu \mathrm{g} / \mathrm{ml}$ of $\mathrm{NaHCO}_{3}$, as previously described $^{58}$. 


$$
\text { Jeje TO, et al. }
$$

\section{Plant material and extract preparation}

Fresh samples of whole Phyllanthus plants were collected from Ado-Ekiti, Nigeria. The whole plants were air-dried and then pulverized with a mortar and pestle.

\section{Reagents}

Antibodies against NF-кB p65 (sc-8008) were obtained from Santa Cruz Biotechnology.

\section{GIA of $P$. falciparum}

The antiplasmodial activity of the extract was assessed on cultured $P$. falciparum HB3 parasites by means of microscopy as previously described ${ }^{58}$. The extract was weighed, dissolved in distilled water, and filter-sterilized $(0.45 \mu \mathrm{m}$ Millipore filter) to make a stock solution with a concentration of $5000 \mu \mathrm{g} / \mathrm{ml}$. The working solution (concentration, $200 \mu \mathrm{g} / \mathrm{ml}$ ) was made by diluting the stock solution with complete parasite media. One hundred and fifty microliters of $P$. falciparum parasite culture suspension, earlier synchronized to the ring stage with 5\% sorbitol, was aliquoted into the wells of a 96-well microtiter plate to a final hematocrit of $2 \%$ and parasitemia of $0.5 \%$ (with fresh Type $\mathrm{AB}$ erythrocytes). The cultures were incubated at $37^{\circ} \mathrm{C}$, with $5 \% \mathrm{CO}_{2}$ and $5 \% \mathrm{O}_{2}$. At 48 -hour post-incubation, $5 \mu \mathrm{l}$ of complete medium was added to each culture. Artemisinin was used as a positive control whereas wells containing no drug but culture at the same parasitemia and hematocrit served as a negative control. Evaluation of the 
Jeje TO, et al.

outcome of the in vitro GIA was carried out 96-hour post-incubation, when the cultures were

mostly in the late trophozoite stage, by means of microscopy. The experiment was carried out 3 times and each experiment was done in triplicate.

\section{P. falciparum invasion assay}

For the invasion assays, purified schizont-infected erythrocytes were prepared by using the Percoll-Sorbitol method ${ }^{58-60}$. Briefly, the medium was removed from the parasite culture by centrifugation at $650 \times g$ for 5 minutes at room temperature. The packed erythrocytes were then resuspended to $50 \%$ hematocrit and put on a gradient made from $70 \%$ and $40 \%$ Percoll-Sorbitol solution. The gradient was then centrifuged at $16,200 \times g$ for 20 minutes at $20^{\circ} \mathrm{C}$ with no brake. Infected erythrocytes were collected from the 40/70 interface and washed twice with incomplete medium. A smear was made to assess the purity and estimate the number of cells by use of a hemocytometer. Purified schizonts were mixed with complete medium to obtain a hematocrit of $1 \%$, and fresh $\mathrm{AB}$ erythrocytes were added for a total parasitemia of $2 \%$. Cultures (150 $\mu \mathrm{l})$ containing the compounds, Niranthin (0.01 ug/ul), Quercetin (0.03 ug/ul), Astragalin (0.03 ug/ul), Catechin $(0.05 \mathrm{ug} / \mathrm{ul})$ and PE $(0.2 \mathrm{ug} / \mathrm{ul})$ were transferred into 96 -well plates. The compounds were dissolved based on their solubility in DMSO, and the final DMSO concentration was $0.1 \%$. The cultures were then incubated for 24 hours at $37^{\circ} \mathrm{C}$, with $5 \% \mathrm{CO}_{2}$ and $5 \% \mathrm{O}_{2}$. Three independent assays were done in triplicate. Culture supernatants were aspirated and the cell 
Jeje TO, et al.

pellets were smeared and stained with Giemsa stain. Parasitemia was measured at the ring stage (appropriately 24 hours post-incubation).

\section{$P$. falciparum development assay}

For the $P$. falciparum development assay, purified schizont-infected erythrocytes were prepared by using the Percoll-Sorbitol method, as discussed above. Fresh AB erythrocytes were incubated with the plant extract for 1 hour after which they were washed three times. Purified schizonts were mixed with complete medium to obtain a hematocrit of $1 \%$, and the washed erythrocytes were added for a total parasitemia of $2 \%$. The non-treated group and a group without washing after treatment served as control groups. Cultures $(150 \mu \mathrm{l})$ were transferred into 96-well plates and the extract was added to a final concentration of appropriately $200 \mu \mathrm{g} / \mathrm{ml}$. Cultures were incubated for 24 hours at $37^{\circ} \mathrm{C}$, with $5 \% \mathrm{CO}_{2}$ and $5 \% \mathrm{O}_{2}$. Three independent assays were done in triplicate. Culture supernatants were aspirated and the cell pellets were smeared and stained with Giemsa stain. Parasitemia was measured at the ring stage (appropriately 24 hours post-incubation).

\section{Assessment of $P$. berghei parasitemia}

Blood smears were obtained daily from all infected mice and stained with Giemsa stain.

Parasitemia was assessed by counting at least $3 \times 10^{3}$ erythrocytes. 
Jeje TO, et al.

\section{Assessment of vascular leakage}

Vascular leakage was measured as previously described ${ }^{26}$. Mice were injected intravenously with $200 \mu \mathrm{l}$ of $2 \%$ Evans Blue (Nacalai Tesque) at 5 days post-infection with $5 \times 10^{6} P$. berghei-infected erythrocytes. Mice were sacrificed 1-hour post-Evans Blue injection; brains were isolated, photographed, and then weighed. Brains were then placed in $2 \mathrm{ml}$ of formamide for 48 hours at $37^{\circ} \mathrm{C}$. The Evans Blue concentration was measured at $620 \mathrm{~nm}$ in an Multi Detection Microplate Reader (Power scan HT, DS Pharma Biomedical) by using $100 \mu$ of solution. The concentration of Evans Blue was calculated by using a standard curve starting at $200 \mu \mathrm{g} / \mathrm{ml}$. Evans Blue content is expressed as “ $\mu \mathrm{g}$ Evans Blue/g brain” in Figure 5D.

\section{Quantitative determination of cell viability ( $\mathrm{LDH}$ assay)}

Cytotoxicity induced by PE was measured as previously described ${ }^{61}$. Cell viability was monitored by measuring lactate dehydrogenase (LDH) leakage into the culture medium by using the CytoTox96 Non-Radio Cytotoxicity Assay kit (Promega). For adherent cells (HFFs, IMR-32 cells, and U-251 cells.), the cells were seeded in the plate at $150 \mu \mathrm{l}$ and incubated at $37^{\circ} \mathrm{C}$, with $5 \% \mathrm{CO}_{2}$ and $5 \% \mathrm{O}_{2}$. After 24 hours, the old media were aspirated and replaced with new media containing $200 \mu \mathrm{g} / \mathrm{ml}$ of extract. The cells and the extracts were then incubated at $37^{\circ} \mathrm{C}$, with $5 \%$ $\mathrm{CO}_{2}$ and $5 \% \mathrm{O}_{2}$ for various hours, as indicated. For the suspension cells (i.e., MOLT-4 cells), the 
Jeje TO, et al.

cells were seeded in the plate at the appropriate culture volume with the extract at a final concentration of $200 \mu \mathrm{g} / \mathrm{ml}$ and incubated at $37^{\circ} \mathrm{C}$, with $5 \% \mathrm{CO}_{2}$ and $5 \% \mathrm{O}_{2}$. Culture supernatant was collected and centrifuged at $20,000 \times g$ for 5 for $5 \mathrm{~min}$, and then the LDH activity in the cell-free supernatant was measured according to the manufacturer's instructions by using Multi Detection Microplate Reader (Power scan HT, DS Pharma Biomedical). Cell-free medium was used as a negative control. Culture supernatant from TritonX-100 (0.1\%) treated cells (to kill all the cells) was used as a positive control.

\section{$\mathrm{IC}_{50}$ determination for $\mathrm{PE}$}

To calculate the $\mathrm{IC}_{50}$ of PE against $P$. falciparum, the GIA assay was performed using $12.5,25,50,100$, and $200 \mu \mathrm{g} / \mathrm{ml}$ of PE. The parasite numbers in the PE-treated cells divided by those in the non-treated cells are shown as the "inhibition rate" in Figure 1D.

\section{Quantitative RT-PCR}

Total RNA was extracted from the cells with Direct-zol RNA MicroPrep (Zymo Research), and cDNA was synthesized by using Verso Reverse transcription (Thermo Fisher Scientific). Quantitative RT-PCR was performed by using the Go-Taq Real-Time PCR system (Promega), as previously described ${ }^{60}$. The values were normalized to the amount of 
Jeje TO, et al.

glyceraldehyde 3-phosphate dehydrogenase (GAPDH). The primer sequences are listed in Table

S1.

\section{Measurement of NF-кB promoter activity}

Cells were stimulated with PMA/ionomycin and luciferase activities in cell lysates were

measured as previously described ${ }^{26}$. To measure the luciferase activity, whole cells were collected $0,1,2,3,4$, and 5 hours post-stimulation, then lysed with $100 \mu$ of lysis buffer (Promega) and sonicated. After centrifugation at $20,000 \times g$ at $4{ }^{\circ} \mathrm{C}$, the luciferase activity of the supernatant was measured by using the Dual Luciferase Reporter Assay System (Promega) and a GLOMAX 20/20 luminometer (Promega).

\section{Immunofluorescence assays}

MOLT-4 cells were cultured at $1 \times 10^{5}$ cells per well, with or without drug treatment after stimulation with PMA/ionomycin for various periods of time. The cells were then pre-fixed with ice-cold methanol for 1 hour at $-20^{\circ} \mathrm{C}$, after which they were fixed with paraformaldehyde (PFA, $1 \%$ in PBS buffer) at $4^{\circ} \mathrm{C}$ for 1 hour. Next, the cells were blocked with $1 \%$ BSA in PBS at room temperature for 1 hour. The cells were thereafter incubated with the primary anti-NF- $\kappa \mathrm{B}$ antibody for 1 hour at room temperature, followed by incubation with secondary antibodies (Anti- mouse FITC) for 1 hour at room temperature in the dark. After washing the cells with PBS, 
Jeje TO, et al.

cells were stained with DAPI for 5 minutes at room temperature in the dark and observed with fluorescence microscopy (BX-40, Olympus/Axiocam 305, Zeiss).

\section{Transfection of reporter plasmids}

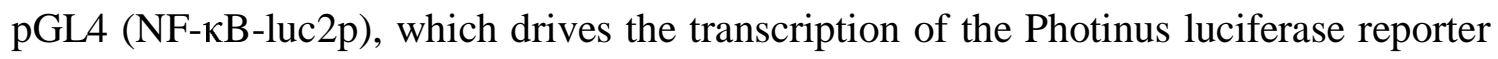
gene, and the Renilla luciferase-expressing plasmid pRL-TK were co-transfected into cells by using lipofectamine 2000 (Invitrogen).

\section{Detection of Caspase 3/7 activity}

IMR-32 cells were seeded in 96-well plates $\left(3 \times 10^{4}\right.$ cells/well). After 24 hours, the medium was changed and the cells were treated with PE $(200 \mu \mathrm{g} / \mathrm{ml})$ or staurosporine $(1 \mu \mathrm{M})$ as a positive control. After 6 hours of treatment, induction of apoptosis was determined by measurement of caspase-3/7 activity using the luminometric Caspase-Glo 3/7 assay (Promega) according to the manufacturer's protocol and a microplate reader (Microplate Reader SH900), as previously described ${ }^{61}$.

\section{Mouse sepsis model}

Eight-week-old female C57BL/6N mice were obtained from Charles River Laboratories

Japan. Sepsis was induced by LPS $(20 \mathrm{mg} / \mathrm{kg}$ ) injection by intraperitoneally (i.p.). Mice were pre- 
Jeje TO, et al.

treated with PE or PBS for 2 days by oral treatment. Four hours after LPS injection, serum were collected for ELISA.

\section{Quantification of IFN- $\gamma$ in mouse serum}

A mouse IFN- $\gamma$ ELISA kit (RayBiotech) was used according to the manufacturer's instructions. Briefly, $100 \mu \mathrm{l}$ of mouse serum and the standard were added to a 96-well microplate coated with anti-mouse IFN- $\gamma$ (immobilized antibody). The plate was then incubated at room temperature for 2.5 hours with gentle shaking. After washing 4 times, $100 \mu$ of prepared biotinylated anti-Mouse IFN- $\gamma$ was added and incubated at room temperature for 1 hour with gentle shaking. The wells were again washed 4 times and $100 \mu \mathrm{l}$ of HRP-conjugated Streptavidin solution was added and incubated with gentle shaking for 45 minutes. The plate was then washed and One-Step substrate reagent (3,3,5,5-tetramethylbenzidine) was added in the dark with gentle shaking. After 30 minutes of incubation, the reaction was stopped by adding $50 \mu$ of $2 \mathrm{~N}$ sulphuric acid, and the color intensity was measured at $450 \mathrm{~nm}$ by using the microplate reader. A curve was prepared, plotting the absorbance at $450 \mathrm{~nm}$ against the concentration of IFN- $\gamma$ in the standard wells. By comparing the absorbance of the samples to this curve, the concentration of IFN- $\gamma$ in the samples was determined.

\section{Statistical analysis}


Jeje TO, et al.

All statistical analyses were performed by using Prism 8 (GraphPad), as previously described $^{26,61}$. All experimental points and $n$ values represent an average of three biological replicates (three independent experiments). The statistical significance of differences in mean values was analyzed by using an unpaired two-tailed Student's t-test. And the Mann-Whitney U test or Kruskal-Wallis test was used to analyze the differences between means with $95 \%$ confidence interval. $P$ values less than 0.05 were considered to be statistically significant. The statistical significance of differences in survival times of mice between two groups was analyzed by using the Kaplan-Meier survival analysis Log rank test. 
Jeje TO, et al.

\section{REFERENCES}

1 WHO. World Malaria Report 2019. (2019).

2 WHO. The world health report 2002 - Reducing Risks, Promoting Healthy Life. World health report (2002).

3 Anstey, N. M., Russell, B., Yeo, T. W. \& Price, R. N. The pathophysiology of vivax malaria. Trends Parasitol 25, 220-227, doi:10.1016/j.pt.2009.02.003 (2009).

4 Miller, L. H., Baruch, D. I., Marsh, K. \& Doumbo, O. K. The pathogenic basis of malaria. Nature 415, 673-679, doi:10.1038/415673a (2002).

5 Chen, Q., Schlichtherle, M. \& Wahlgren, M. Molecular aspects of severe malaria. Clin Microbiol Rev 13, 439-450, doi:10.1128/cmr.13.3.439-450.2000 (2000).

6 Renslo, A. R. Antimalarial Drug Discovery: From Quinine to the Dream of Eradication. ACS Med Chem Lett 4, 1126-1128, doi:10.1021/ml4004414 (2013).

7 Miller, L. H. \& Su, X. Artemisinin: discovery from the Chinese herbal garden. Cell 146, 855-858, doi:10.1016/j.cell.2011.08.024 (2011).

8 Dondorp, A. M. et al. Artemisinin resistance in Plasmodium falciparum malaria. $N$ Engl J Med 361, 455-467, doi:10.1056/NEJMoa0808859 (2009).

9 Burns, A. L. et al. Targeting malaria parasite invasion of red blood cells as an antimalarial strategy. FEMS Microbiol Rev 43, 223-238, doi:10.1093/femsre/fuz005 (2019).

10 Cowman, A. F., Berry, D. \& Baum, J. The cellular and molecular basis for malaria parasite invasion of the human red blood cell. J Cell Biol 198, 961-971, doi:10.1083/jcb.201206112 (2012).

11 Cowan, M. M. Plant products as antimicrobial agents. Clin Microbiol Rev 12, 564-582 (1999).

12 Adebayo, J. O. \& Krettli, A. U. Potential antimalarials from Nigerian plants: a review. $J$ Ethnopharmacol 133, 289-302, doi:10.1016/j.jep.2010.11.024 (2011).

13 Willcox, M. L. \& Bodeker, G. Traditional herbal medicines for malaria. Bmj 329, 11561159, doi:10.1136/bmj.329.7475.1156 (2004).

14 Jantan, I., Haque, M. A., Ilangkovan, M. \& Arshad, L. An Insight Into the Modulatory Effects and Mechanisms of Action of Phyllanthus Species and Their Bioactive 
Jeje TO, et al.

Metabolites on the Immune System. Front Pharmacol 10, 878, doi:10.3389/fphar.2019.00878 (2019).

15 Ifeoma, O., Samuel, O., Itohan, A. M. \& Adeola, S. O. Isolation, fractionation and evaluation of the antiplasmodial properties of Phyllanthus niruri resident in its chloroform fraction. Asian Pac J Trop Med 6, 169-175, doi:10.1016/s19957645(13)60018-8 (2013).

16 Mustofa, Sholikhah, E. N. \& Wahyuono, S. In vitro and in vivo antiplasmodial activity and cytotoxicity of extracts of Phyllanthus niruri L. herbs traditionally used to treat malaria in Indonesia. Southeast Asian J Trop Med Public Health 38, 609-615 (2007).

17 Nishanth, G. \& Schlüter, D. Blood-Brain Barrier in Cerebral Malaria: Pathogenesis and Therapeutic Intervention. Trends Parasitol 35, 516-528, doi:10.1016/j.pt.2019.04.010 (2019).

18 Hunt, N. H. et al. Murine cerebral malaria: the whole story. Trends Parasitol 26, 272-274, doi:10.1016/j.pt.2010.03.006 (2010).

19 Craig, A. G. et al. The role of animal models for research on severe malaria. PLoS Pathog 8, e1002401, doi:10.1371/journal.ppat.1002401 (2012).

20 Amani, V. et al. Involvement of IFN-gamma receptor-medicated signaling in pathology and anti-malarial immunity induced by Plasmodium berghei infection. Eur J Immunol 30, 1646-1655, doi:10.1002/1521-4141(200006)30:6<1646::Aid-immu1646>3.0.Co;2-0 (2000).

21 Schofield, L. \& Grau, G. E. Immunological processes in malaria pathogenesis. Nat Rev Immunol 5, 722-735, doi:10.1038/nri1686 (2005).

22 Yañez, D. M., Manning, D. D., Cooley, A. J., Weidanz, W. P. \& van der Heyde, H. C. Participation of lymphocyte subpopulations in the pathogenesis of experimental murine cerebral malaria. J Immunol 157, 1620-1624 (1996).

23 Belnoue, E. et al. Control of pathogenic CD8+ T cell migration to the brain by IFNgamma during experimental cerebral malaria. Parasite Immunol 30, 544-553, doi:10.1111/j.1365-3024.2008.01053.x (2008).

24 Claser, C. et al. CD8+ T cells and IFN- $\gamma$ mediate the time-dependent accumulation of infected red blood cells in deep organs during experimental cerebral malaria. PLoS One 6, e18720, doi:10.1371/journal.pone.0018720 (2011). 
Jeje TO, et al.

25 Medana, I. et al. Fas ligand (CD95L) protects neurons against perforin-mediated T lymphocyte cytotoxicity. J Immunol 167, 674-681, doi:10.4049/jimmunol.167.2.674 (2001).

26 Bando, H. et al. CXCR4 regulates Plasmodium development in mouse and human hepatocytes. J Exp Med 216, 1733-1748, doi:10.1084/jem.20182227 (2019).

27 Kaur, N., Kaur, B. \& Sirhindi, G. Phytochemistry and Pharmacology of Phyllanthus niruri L.: A Review. Phytother Res 31, 980-1004, doi:10.1002/ptr.5825 (2017).

28 Asare, G. A. et al. Acute toxicity studies of aqueous leaf extract of Phyllanthus niruri. Interdiscip Toxicol 4, 206-210, doi:10.2478/v10102-011-0031-9 (2011).

29 Wilson, D. W., Langer, C., Goodman, C. D., McFadden, G. I. \& Beeson, J. G. Defining the timing of action of antimalarial drugs against Plasmodium falciparum. Antimicrob Agents Chemother 57, 1455-1467, doi:10.1128/aac.01881-12 (2013).

30 Recuenco, F. C. et al. Gellan sulfate inhibits Plasmodium falciparum growth and invasion of red blood cells in vitro. Sci Rep 4, 4723, doi:10.1038/srep04723 (2014).

31 Mustofa, S., E. N. \& Wahyuono, S. . Antiplasmodial activity of fractions isolated from methanolic extract of meniran herb (Phyllanthus niruri L) traditionally used to treat malaria. Berkala limu Kedokteran Maret 39, 7-13 (2007).

32 Villegas-Mendez, A. et al. IFN- $\gamma$-producing CD4+ T cells promote experimental cerebral malaria by modulating CD8+ T cell accumulation within the brain. J Immunol 189, 968979, doi:10.4049/jimmunol.1200688 (2012).

33 Punsawad, C. Effect of malaria components on blood mononuclear cells involved in immune response. Asian Pac J Trop Biomed 3, 751-756, doi:10.1016/s22211691(13)60151-3 (2013).

34 Beg, A. A., Finco, T. S., Nantermet, P. V. \& Baldwin, A. S., Jr. Tumor necrosis factor and interleukin-1 lead to phosphorylation and loss of I kappa B alpha: a mechanism for NF-kappa B activation. Mol Cell Biol 13, 3301-3310, doi:10.1128/mcb.13.6.3301 (1993).

35 Hunt, N. H. et al. Immunopathogenesis of cerebral malaria. Int J Parasitol 36, 569-582, doi:10.1016/j.ijpara.2006.02.016 (2006).

36 Lackner, P. et al. Apoptosis in experimental cerebral malaria: spatial profile of cleaved caspase-3 and ultrastructural alterations in different disease stages. Neuropathol Appl Neurobiol 33, 560-571, doi:10.1111/j.1365-2990.2007.00833.x (2007). 
Jeje TO, et al.

37 Earnshaw, W. C., Martins, L. M. \& Kaufmann, S. H. Mammalian caspases: structure, activation, substrates, and functions during apoptosis. Annu Rev Biochem 68, 383-424, doi:10.1146/annurev.biochem.68.1.383 (1999).

38 Nakamura, S. et al. IFN-gamma-dependent and -independent mechanisms in adverse effects caused by concomitant administration of IL-18 and IL-12. J Immunol 164, 33303336, doi:10.4049/jimmunol.164.6.3330 (2000).

39 Tse, E. G., Korsik, M. \& Todd, M. H. The past, present and future of anti-malarial medicines. Malar J 18, 93, doi:10.1186/s12936-019-2724-z (2019).

40 Kumar, S., Bhardwaj, T. R., Prasad, D. N. \& Singh, R. K. Drug targets for resistant malaria: Historic to future perspectives. Biomed Pharmacother 104, 8-27, doi:10.1016/j.biopha.2018.05.009 (2018).

41 Oliveira, A. B. et al. Plant-derived antimalarial agents: new leads and efficient phythomedicines. Part I. Alkaloids. An Acad Bras Cienc 81, 715-740, doi:10.1590/s000137652009000400011 (2009).

42 Krettli, A. U. Antimalarial drug discovery: screening of Brazilian medicinal plants and purified compounds. Expert Opin Drug Discov 4, 95-108, doi:10.1517/17530050802678127 (2009).

43 Caldelari, R. et al. Transcriptome analysis of Plasmodium berghei during exoerythrocytic development. Malar J 18, 330, doi:10.1186/s12936-019-2968-7 (2019).

44 Vaughan, A. M., Aly, A. S. \& Kappe, S. H. Malaria parasite pre-erythrocytic stage infection: gliding and hiding. Cell Host Microbe 4, 209-218, doi:10.1016/j.chom.2008.08.010 (2008).

45 Kapishnikov, S. et al. Mode of action of quinoline antimalarial drugs in red blood cells infected by Plasmodium falciparum revealed in vivo. Proc Natl Acad Sci U S A 116, 22946-22952, doi:10.1073/pnas.1910123116 (2019).

46 Greenbaum, D. C. et al. A role for the protease falcipain 1 in host cell invasion by the human malaria parasite. Science 298, 2002-2006, doi:10.1126/science.1077426 (2002).

47 Sijwali, P. S. et al. Plasmodium falciparum cysteine protease falcipain-1 is not essential in erythrocytic stage malaria parasites. Proc Natl Acad Sci U S A 101, 8721-8726, doi:10.1073/pnas.0402738101 (2004). 
48 Barcellini, W. New Insights in the Pathogenesis of Autoimmune Hemolytic Anemia. Transfus Med Hemother 42, 287-293, doi:10.1159/000439002 (2015).

49 Cui, L. \& Su, X. Z. Discovery, mechanisms of action and combination therapy of artemisinin. Expert Rev Anti Infect Ther 7, 999-1013, doi:10.1586/eri.09.68 (2009).

50 Angulo, I. \& Fresno, M. Cytokines in the pathogenesis of and protection against malaria. Clin Diagn Lab Immunol 9, 1145-1152, doi:10.1128/cdli.9.6.1145-1152.2002 (2002).

51 Combes, V., Guillemin, G. J., Chan-Ling, T., Hunt, N. H. \& Grau, G. E. The crossroads of neuroinflammation in infectious diseases: endothelial cells and astrocytes. Trends Parasitol 28, 311-319, doi:10.1016/j.pt.2012.05.008 (2012).

52 Drewry, L. L. \& Harty, J. T. Balancing in a black box: Potential immunomodulatory roles for TGF- $\beta$ signaling during blood-stage malaria. Virulence 11, 159-169, doi:10.1080/21505594.2020.1726569 (2020).

53 Mimche, P. N., Taramelli, D. \& Vivas, L. The plant-based immunomodulator curcumin as a potential candidate for the development of an adjunctive therapy for cerebral malaria. Malar J 10 Suppl 1, S10, doi:10.1186/1475-2875-10-s1-s10 (2011).

54 Nworu, C. S., Akah, P. A., Okoye, F. B., Proksch, P. \& Esimone, C. O. The effects of Phyllanthus niruri aqueous extract on the activation of murine lymphocytes and bone marrow-derived macrophages. Immunol Invest 39, 245-267, doi:10.3109/08820131003599585 (2010).

55 Abd El-Aziz, T. A., Mohamed, R. H., Pasha, H. F. \& Abdel-Aziz, H. R. Catechin protects against oxidative stress and inflammatory-mediated cardiotoxicity in adriamycintreated rats. Clin Exp Med 12, 233-240, doi:10.1007/s10238-011-0165-2 (2012).

56 Comalada, M. et al. In vivo quercitrin anti-inflammatory effect involves release of quercetin, which inhibits inflammation through down-regulation of the NF-kappaB pathway. Eur J Immunol 35, 584-592, doi:10.1002/eji.200425778 (2005).

57 Bando, H. et al. Toxoplasma Effector GRA15-Dependent Suppression of IFN- $\gamma$-Induced Antiparasitic Response in Human Neurons. Front Cell Infect Microbiol 9, 140 doi: 10.3389/fcimb.2019.00140. (2019).

58 Nonaka, M. et al. Screening of a library of traditional Chinese medicines to identify antimalarial compounds and extracts. Malar J 17, 244, doi:10.1186/s12936-018-2392-4 (2018). 
Jeje TO, et al.

59 Kaneko, O., Soubes, S.C. \& Miller, L.H. Plasmodium falciparum: invasion of Aotus monkey red blood cells and adaptation to Aotus monkeys. Exp Parasitol 93, 116-119 (1999).

60 Kato, K., Mayer, D.C., Singh, S., Reid, M. \& Miller, L.H. Domain III of Plasmodium falciparum apical membrane antigen 1 binds to the erythrocyte membrane protein $\mathrm{Kx}$. Proc Natl Acad Sci U S A 102, 5552-5557 (2005).

61 Bando, H. et al. Inducible Nitric Oxide Synthase Is a Key Host Factor for Toxoplasma GRA15-Dependent Disruption of the Gamma Interferon-Induced Antiparasitic Human Response. mBio 9, doi:10.1128/mBio.01738-18 (2018). 


\section{Figure 1_Jeje et al.}

bioRxiv preprint doi: https://doi.org/10.1101/2021.07.09.451735; this version posted July 10, 2021. The copyright holder for this preprint (which was not certified by peer review) is the author/funder. All rights reserved. No reuse allowed without permission.

A

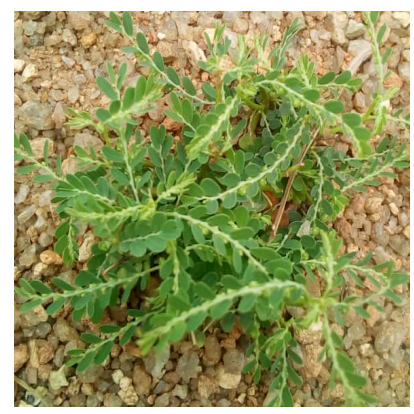

Phyllanthus niruri
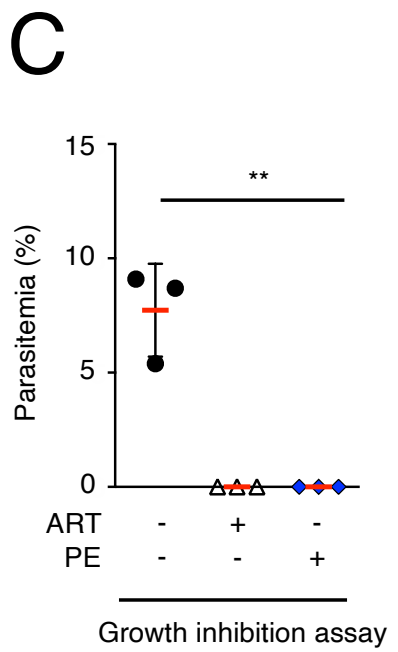

\section{Purification method of} aqueous extract of $P$. niruri (PE)

P. niruri $(100 \mathrm{~g})$ was boiled in $1 \mathrm{~L}$ of water for 1 hour Centrifuged supernatant of boiled water was used for Freeze-dry (1990xg for $30 \mathrm{~min}$ at RT)

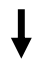

0.2-0.1 $\mathrm{mg} / \mathrm{mL}$ of freeze-dried powder was used for the experiment

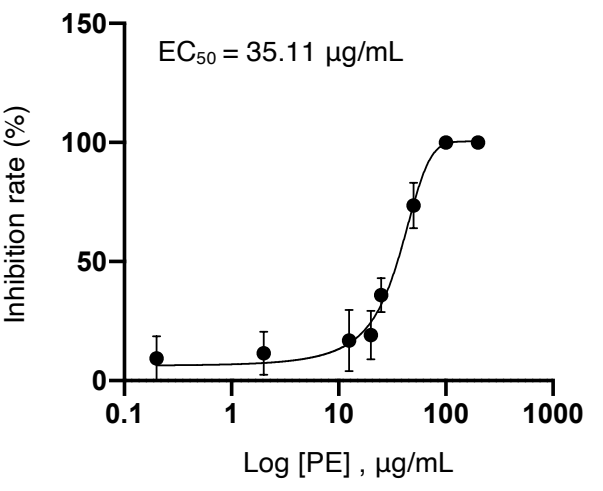

B

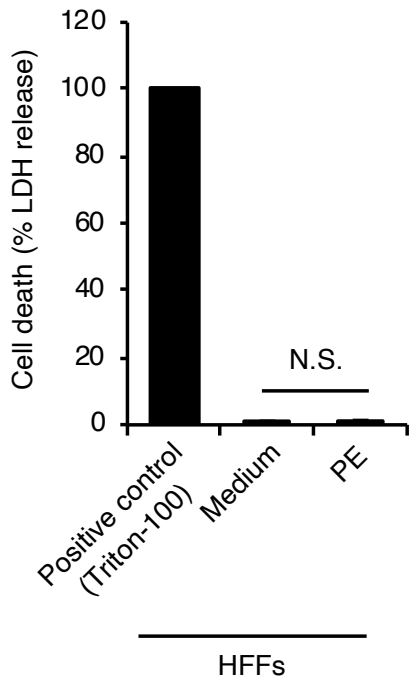


A
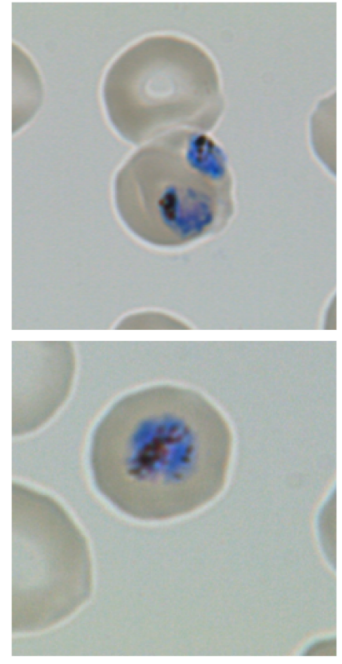

Mock treated
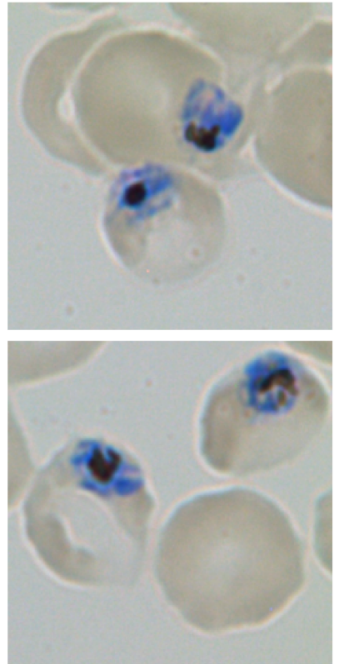

PE treated

$\mathrm{B}$

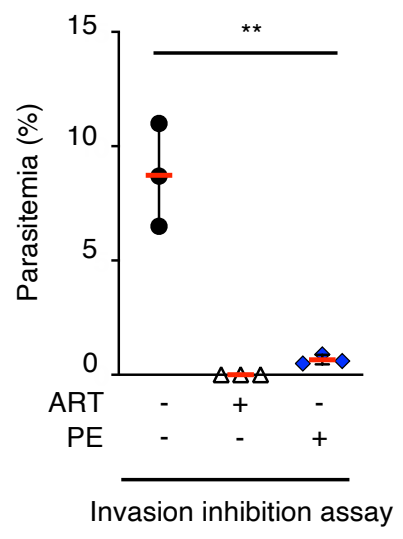

C

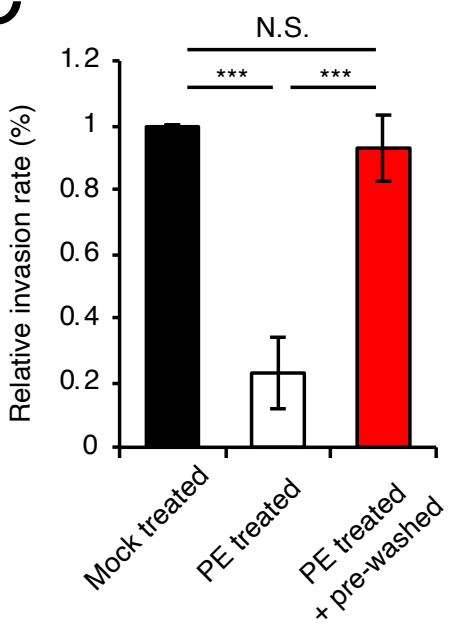

Invasion inhibition assay

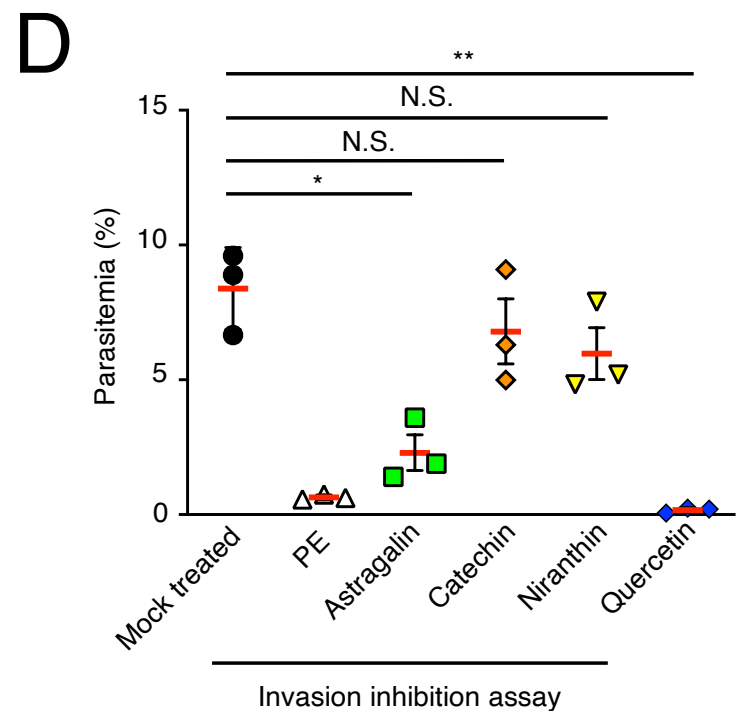

$E$

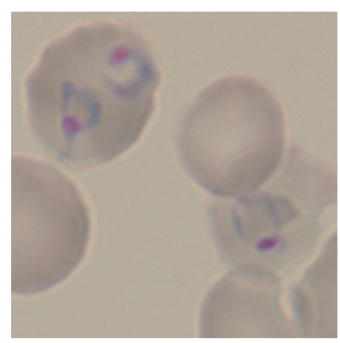

Mock treated

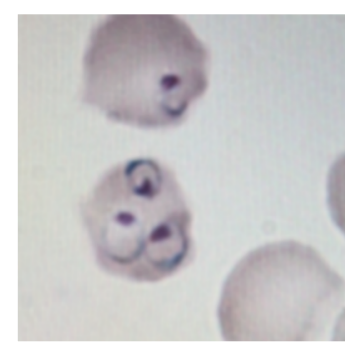

PE treated

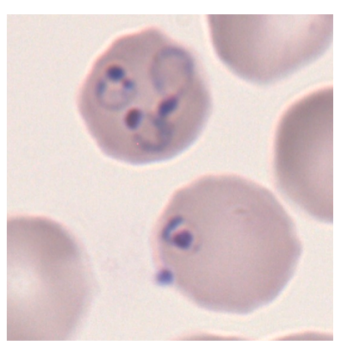

Astragalin treated

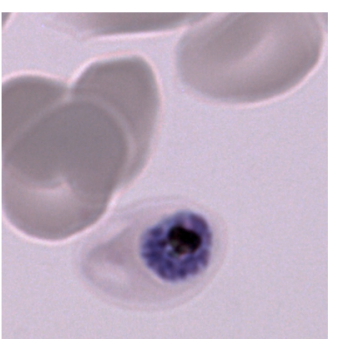

Quercetin treated 
A
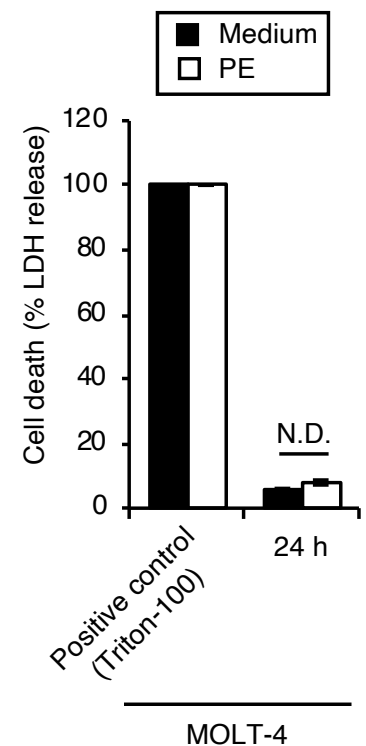

C

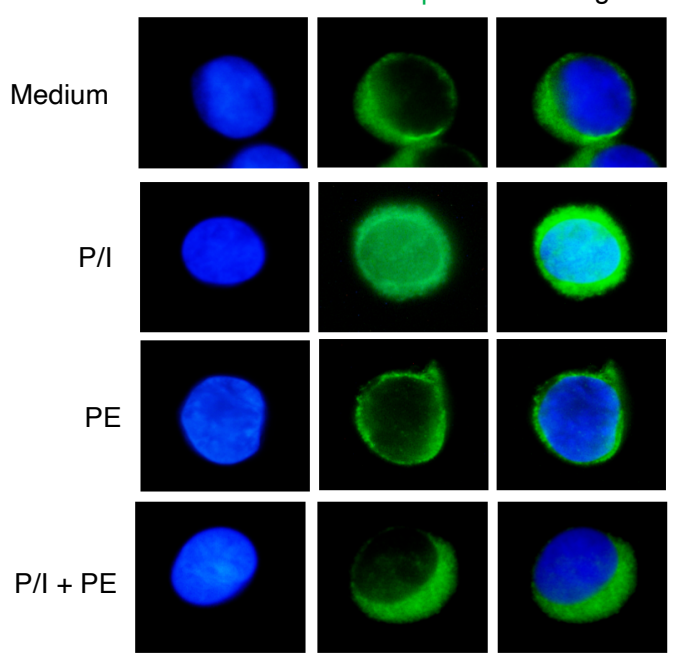

MOLT-4
$\mathrm{B}$
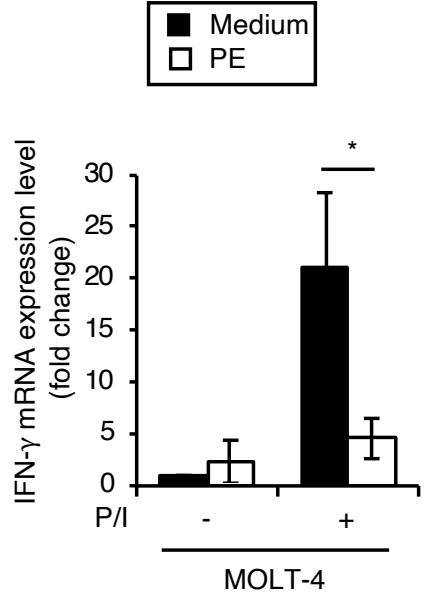

D

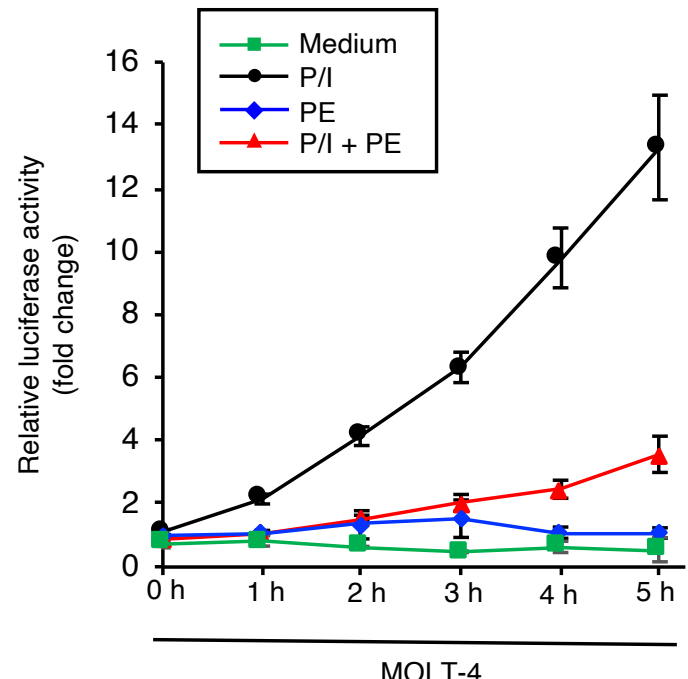


A
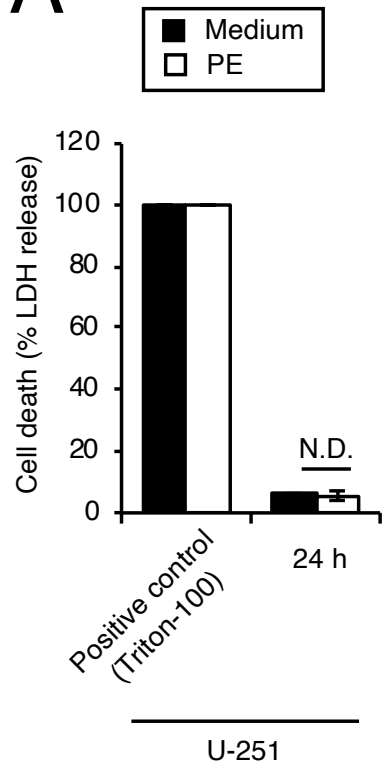

C

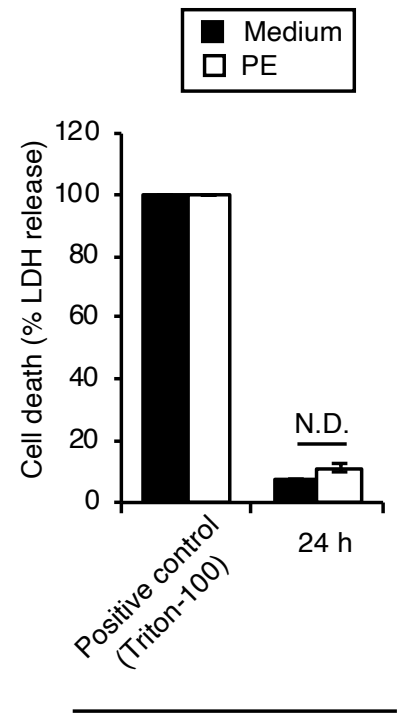

IMR-32
B

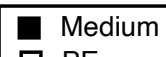

口PE
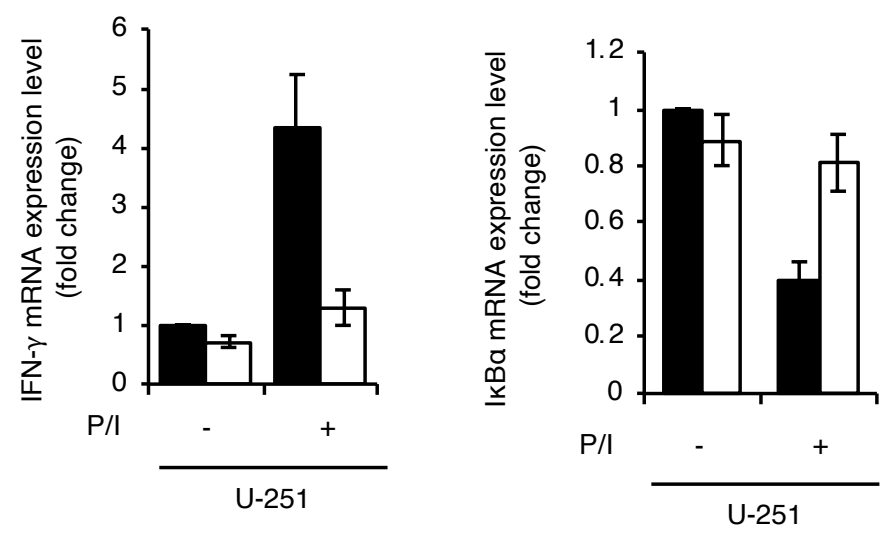

D

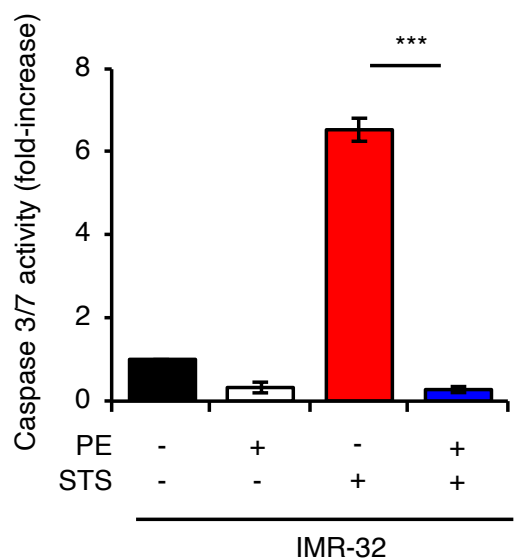

Medium

$\square \mathrm{PE}$ 
Figure 5_Jeje et al.

A

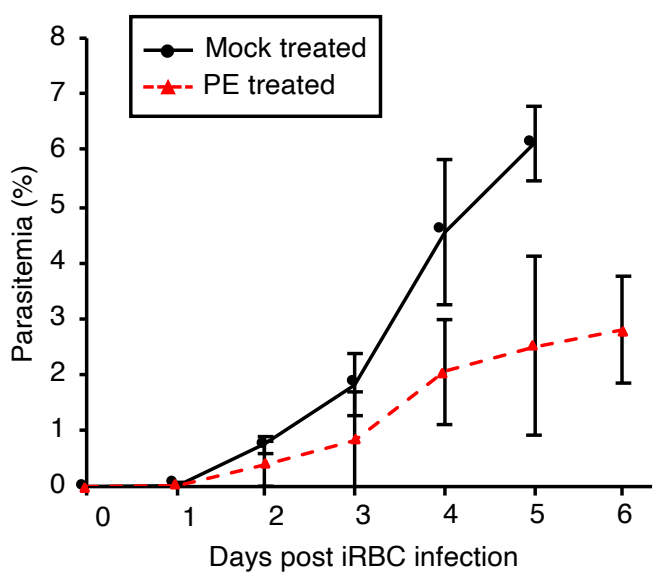

C

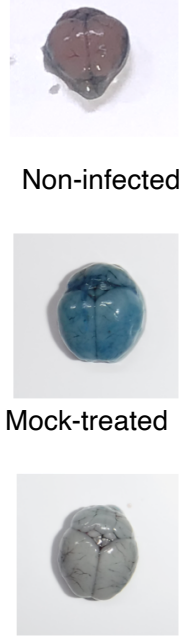

PE-treated
B

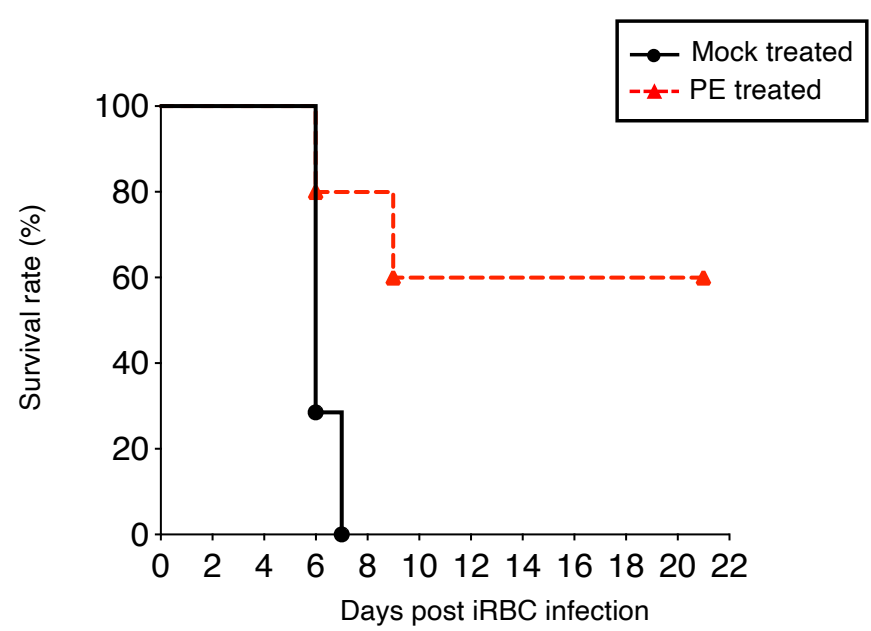

D

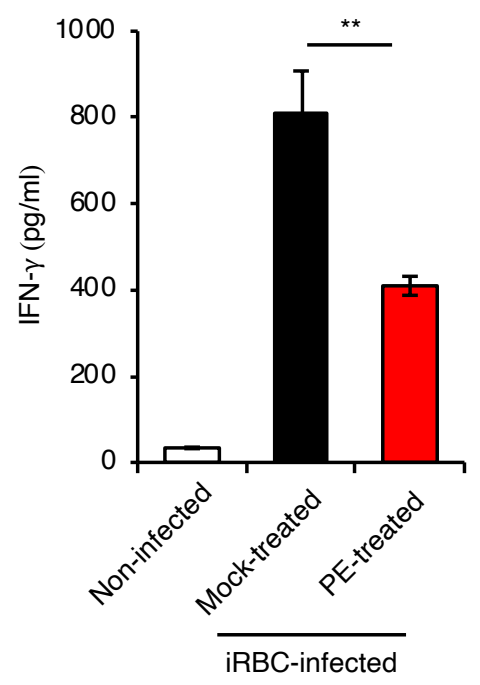




\section{Supplemental Figure 1_Jeje et al.}

A

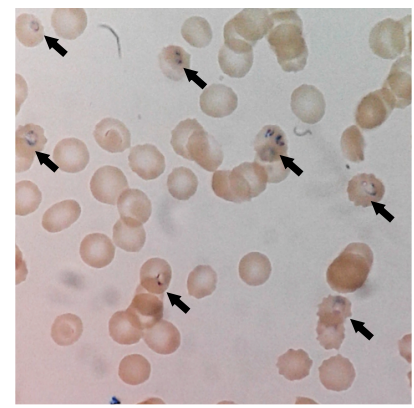

Non-treated

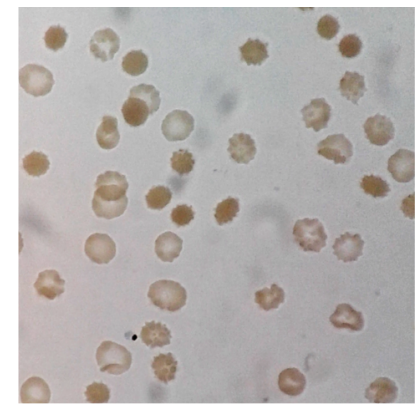

ART-treated

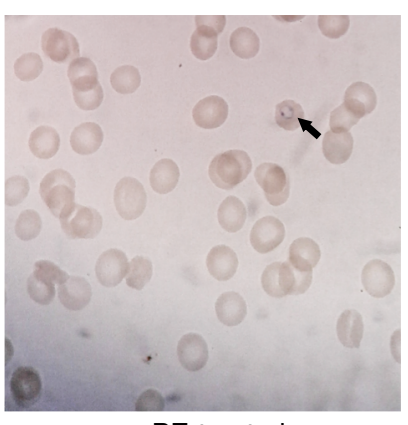

PE-treated 


\section{Supplemental Figure 2_Jeje et al.}

A

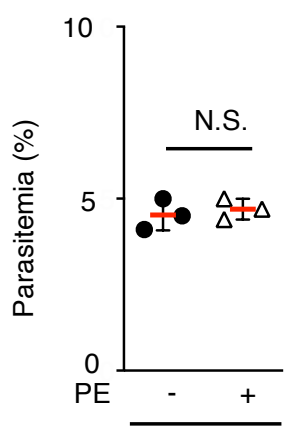

Growth inhibition assay 


\section{Supplemental Figure 3_Jeje et al.}

A
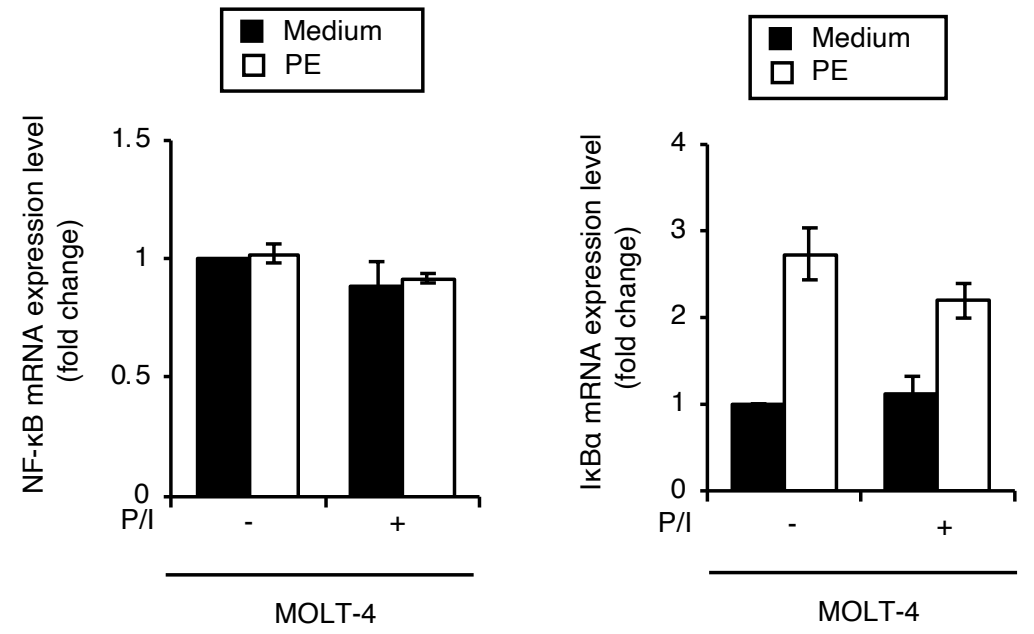
Supplemental Figure 4_Jeje et al.

A

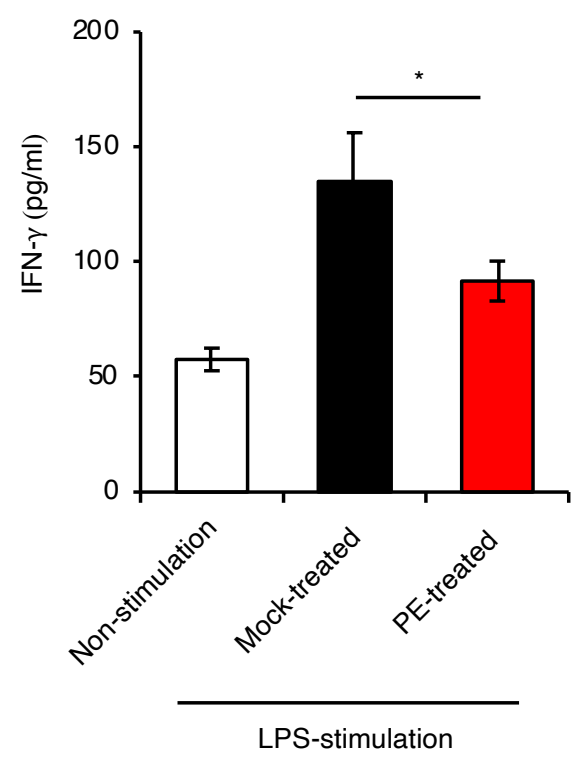

